\title{
Comparative Analysis of Retention and Bite Force in Completely Edentulous Patients with Torus Palatinus Restored with Two Different Denture Designs
}

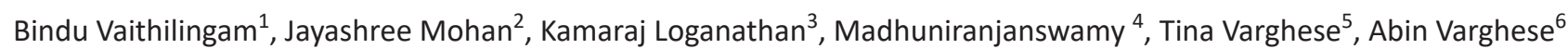

\begin{abstract}
Aim and objective: This study aimed to investigate the retention and bite force in completely edentulous patients with torus palatinus rehabilitated with two designs, one with window to accommodate the tori which is later modified to a horseshoe-shaped complete denture. Materials and methods: A total of 66 patients, with tori requiring complete denture, were included in the study. The retention was measured during 3 months follow-up with both designs. The denture bases with different designs were subjected for evaluation of retention using a Handheld Digital Push-Pull Force Gauge Meter to evaluate the retentive values of the denture bases. The bite force was measured at the first molar region by a custom-built occlusal force meter at 1 week, 1 month and 3 months intervals during follow-up.

Results: The results of the study showed that there was not much significant difference between the two denture designs in terms of their retention. The mean biting force was statistically significant different between both the designs, with the horseshoe design showing higher values compared to the denture with window.

Conclusion: Among the two designs, retention values were approximately the same with both the designs and there was a significant difference in bite force values with the horseshoe-shaped denture.

Clinical significance: Some intraoral anatomical features can negatively affect certain patients and complicate prosthodontic intervention. In this study, the horse shoe-shaped complete denture proved to be an effective treatment option compared to the denture with the window.

Keywords: Bite force, Denture designs, Retention, Torus palatinus.

World Journal of Dentistry (2022): 10.5005/jp-journals-10015-1904
\end{abstract}

\section{INTRODUCTION}

Denture retention is resistance to dislodgement of the denture base from the supporting tissues. ${ }^{1}$ The success of complete dentures depends largely on the relation between the denture and the anatomic structures that support and limit them. ${ }^{2}$ For edentulous patients, who receive dentures, merely providing enough stability and support for the dentures is insufficient; rather, acceptance of dentures require patients to endure a process of adjustment.

A properly constructed denture with satisfactory retention, aids significantly to the patient's comfort and psychological wellbeing, whereas a lack of retention can lead to social isolation due to fear, apprehension and embarrassment caused by loose dentures. ${ }^{3}$ Needless to say, retention dramatically increases psychological acceptance of a complete denture. ${ }^{4}$ The most common factor resulting in lack of retention of a maxillary complete denture is failure to utilize proper anatomical and physiological landmarks as well as recording PPS. ${ }^{5}$

Tori are benign bony outgrowths, which are usually present in the mandible or midline of the hard palate. ${ }^{6}$ The maxillary tori are relatively common, with a prevalence of roughly 27 of 1,000 adults. Globally, they have a prevalence rate of $8-51 \% .{ }^{7}$ Malaysian population, torus palatinus has a prevalence rate of $38 \%-63 \% .{ }^{8}$ Denture fabrication for such patients presents a troublesome scenario, as the tori itself would cause denture instability which in turn would adversely affect the support and retention of the prosthesis, resulting in deleterious forces on the edentulous ridges during its usage. ${ }^{9,10}$ Traditional management
${ }^{1}$ Department of Prosthetic Dentistry, Penang International Dental College, Jalan Bagan Luar, Butterworth, Pulau Pinang, Malaysia

${ }^{2}$ Department of Prosthodontics, Vinayaka Missions Research Foundation (Deemed to be University), Salem, Tamil Nadu, India

${ }^{3,6}$ Department of Oral and Maxillofacial Surgery, Penang International Dental College, Jalan Bagan Luar, Butterworth, Pulau Pinang, Malaysia

${ }^{4}$ Department of Community Dentistry, Penang International Dental College, Jalan Bagan Luar, Butterworth, Pulau Pinang, Malaysia

${ }^{5}$ Department of Periodontology, Penang International Dental College, Jalan Bagan Luar, Butterworth, Pulau Pinang, Malaysia

Corresponding Authors: Bindu Vaithilingam, Department of Prosthetic Dentistry, Penang International Dental College, Jalan Bagan Luar, Butterworth, Pulau Pinang, Malaysia, Phone: 0105095077, e-mail: bindukamaraj@yahoo.in

How to cite this article: Vaithilingam B, Mohan J, Loganathan K, et al. Comparative Analysis of Retention and Bite Force in Completely Edentulous Patients with Torus Palatinus Restored with Two Different Denture Designs. World J Dent 2022;13(2):138-143.

Source of support: Nil

Conflict of interest: None

of torus palatinus can be either surgical or nonsurgical. However, some studies recommend surgical removal of the torus palatinus in extreme cases only, as it could cause several complications that include perforation of the nasal cavities,

() The Author(s). 2022 Open Access This article is distributed under the terms of the Creative Commons Attribution 4.0 International License (https://creativecommons. org/licenses/by-nc/4.0/), which permits unrestricted use, distribution, and non-commercial reproduction in any medium, provided you give appropriate credit to the original author(s) and the source, provide a link to the Creative Commons license, and indicate if changes were made. The Creative Commons Public Domain Dedication waiver (http://creativecommons.org/publicdomain/zero/1.0/) applies to the data made available in this article, unless otherwise stated. 
nerve damage, bone necrosis due to poor refrigeration during surgical drilling, hemorrhage due to section of palatine arteries, dilacerations of the palatine mucosa, fracture of the palatine bone, ${ }^{11}$ postoperative pain, edema, appearance of bony spicules, salivary duct injuries, emphysema, wound dehiscence, and infection. $^{12}$

In this clinical scenario, a study comparing two denture designs, one with a window, ${ }^{13}$ to accommodate the inoperable tori which is later modified to a horseshoe-shaped denture, ${ }^{14}$ was carried out, in terms of retention and bite force with both the designs. Hence, the aim of this within-subject crossover clinical trial was to evaluate the retention and masticatory bite force in patients with torus palatini rehabilitated with two denture designs.

\section{Materials and Methods}

This within-subject crossover clinical trial was carried out in the Department of Prosthetic dentistry in Penang International Dental College, Malaysia. The study was approved by the Internal Review Board of Penang International Dental College, and was carried out after obtaining informed consent from the patients.

A total of 66 completely edentulous subjects with maxillary tori (Fig. 1A) were selected for the study. Participants included 29 men and 37 women, mean age $62.378+7.214$-years, and range $47-70$ years seeking prosthetic treatment with complete dentures.

However, Patients with large tori extending to the soft palate, Patients with large inoperable tori, Patients with pedunculated tori/multiloculated tori, Patients with xerostomia or excessive salivation, Patients with a temporomandibular joint (TMJ)disorders, Patients with history of any systemic and neuromuscular disorder that might affect chewing efficiency of masticatory muscles were excluded from the study.

For each patient complete dentures of two types were made:

- Complete denture with a window (Fig. 1B) which was modified into

- Horse shoe-shaped complete denture (Fig. 1C), after an observational period

Testing apparatus:

- Digital force gauge device to check retention (Fig. 1D)

- Occlusal force meter instrument to check bite force (Fig. 1E)

The patients received the complete denture with a window first, which the patients were asked to wear for a period of three months. The retention of the prosthesis was measured at 3 months follow up period, post-prosthesis placement.

After three months the complete denture with the window was modified to a horseshoe-shaped complete denture, which the patient wore for an additional three months. The retention of the prosthesis was recorded again similar to that of the complete denture with the window.

\section{Measurement of Retention}

The retention of both the prosthesis was measured after three months. The denture bases with different designs were subjected for evaluation of retention using a Handheld Digital Push-Pull Force Gauge Meter to evaluate the retentive values of the denture bases.

The subjects were seated in an upright position, such that the Frankfurt horizontal plane and floor were parallel to each other. The subjects were instructed to partially open their mouth. The maxillary denture base was inserted in the patient's mouth and allowed to remain for a "settling" time of $10 \mathrm{~min}$ before the denture base loop was engaged to the digital force gauge. Traction was carried out at an angle of $45^{\circ}$ to the horizontal plane till the patient informed dislodgement of denture base from the palate. The force required to dislodge the denture base in the mouth was measured in Newton. Each subject were tested for both the denture bases, readings were recorded for each of the denture base.

\section{Bite Force Measurements}

Bite force measurements were made using a custom-built bite force sensor. This bite force sensor consists of two parallel bite plates (made of acrylic structure) embedded with a flexible pressure sensor. The system is connected to a computer where software for reading the pressure changes had been installed. The acrylic structure is placed in the first molar region and the patient is instructed to bite on this acrylic structure to record bite force (Fig. 1F). The sensors showed excellent repeatability $(< \pm 5.8(50 \%$ load $)$ with the capability of measuring a bite force range of $0-20 \mathrm{~kg}$.

The bite force with both the denture designs (complete denture with window and the horseshoe-shaped complete denture) was recorded at one week, one month and three months intervals, during follow-up. The measuring range was set at $0-70 \mathrm{~N}$.

\section{Results}

In the present study, there were $29(44 \%)$ male and $37(56 \%)$ female subjects. The mean age of participants was $62.378+7.214$ and the minimum age was 47 and the maximum age was 70 .

\section{Retention}

In the present study, the mean denture retention of participants in the window group was $5.025+0.427$ and the minimum denture retention was 4.15 and the maximum denture retention was 5.77 .

In present study the mean denture retention of participants in the Horse shoe group was $4.93+0.433$ and the minimum denture retention was 4.04 and the maximum denture retention was 5.73 .

Table 1 shows the overall comparison of retention between the two denture designs at different intervals of time.

There was not much significant difference between the two dentures in terms of their retentiveness as both showed approximately similar values (Fig. 2).

\section{Bite Force}

In the present study, the mean bite force at 1 week in the window group was $40.646+3.772$ and the minimum bite force was 34.57 and maximum bite force was 51.11. The mean bite force of participants in the Horseshoe group at 1 week was $55.05+2.831$ and the minimum bite force was 47.47 and the maximum bite force was 60.39. Figure 3 shows the comparison of the mean bite force at 1 week.

While the mean bite force, at 1 month in the window group was $45.168+3.653$ and the minimum bite force was 37.94 and the maximum bite force was 53.94. The mean bite force of participants in Horseshoe group at 1 month was $59.31+2.937$ and the minimum bite force was 51.31 and the maximum bite force was 64.87. Figure 4 shows the comparison of the mean bite force at 1 month. 


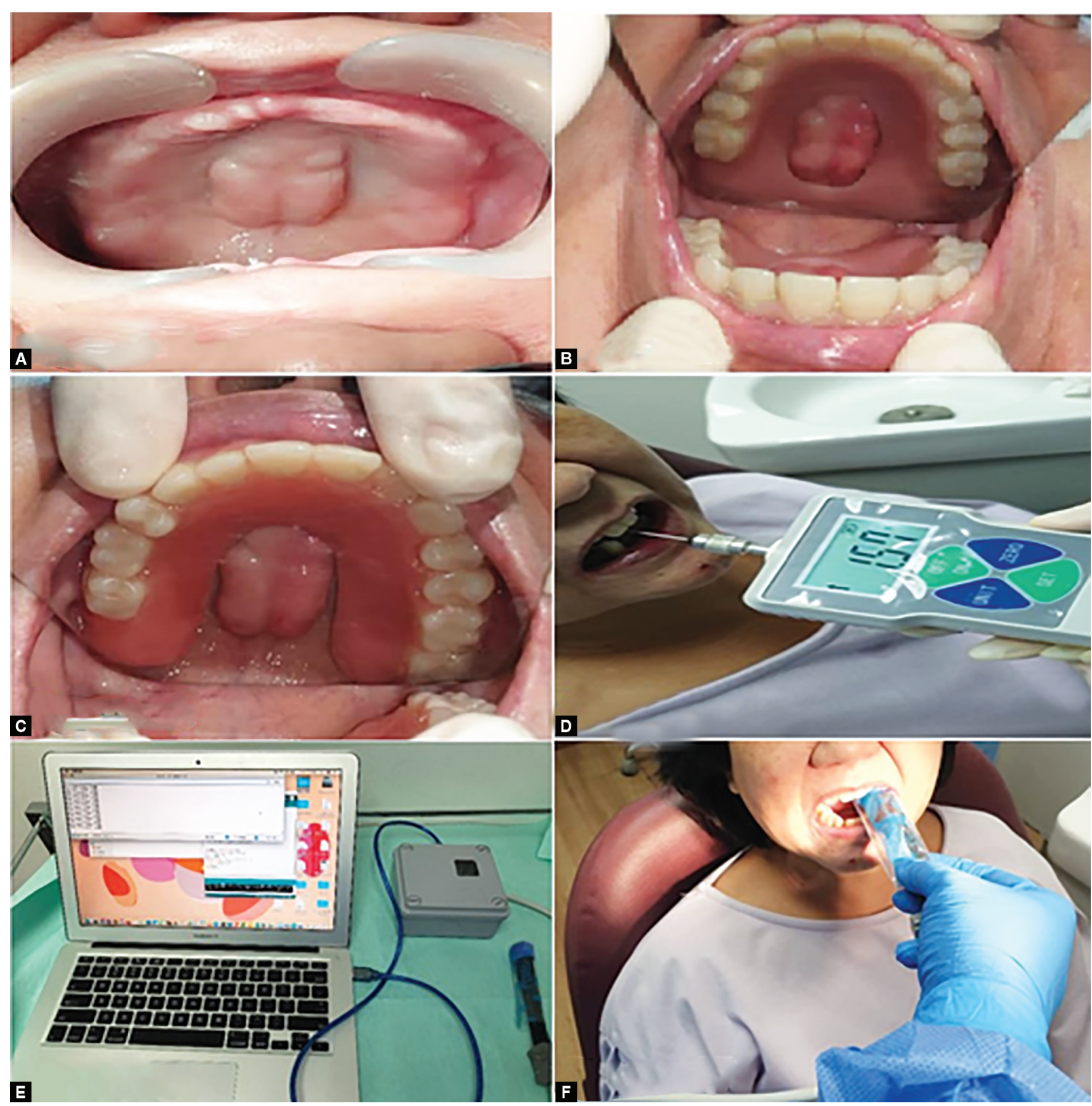

Figs 1A to F: (A) Maxillary tori; (B) Complete denture with window; (C) Horse shoe-shaped complete denture; (D) Digital force gauge device; (E) Occlusal force meter instrument; F: Recording bite force

Table 1: Comparison of retention with two denture designs

\begin{tabular}{|c|c|c|c|c|c|}
\hline & Group & $N$ & Mean & Std. deviation & $p$ \\
\hline \multirow{2}{*}{$\begin{array}{l}\text { Denture } \\
\text { retention at } \\
3 \text { months }\end{array}$} & Window & 66 & 5.0256 & 0.42727 & 0.185 \\
\hline & Horse shoe & 66 & 4.9397 & 0.43367 & \\
\hline
\end{tabular}

In the present study, the mean bite force of participants in the window group at 3 months was $40.646+3.772$ and the minimum bite force was 44.30 and the maximum bite force was 57.66 . The mean bite force of participants in Horseshoe group at 3 months was $63.96+3.24$ and the minimum bite force was 55.04 and the maximum bite force was 69.49 . Figure 5 shows the comparison of the mean bite force at 3 months.

Table 2 shows the overall comparison of bite force between the two dentures at different intervals of time.

The bite force recorded was found to be high in the horseshoe group in all three intervals of the study (1st week, 1st month and the $3 r d$ month) and it was statistically significant. 


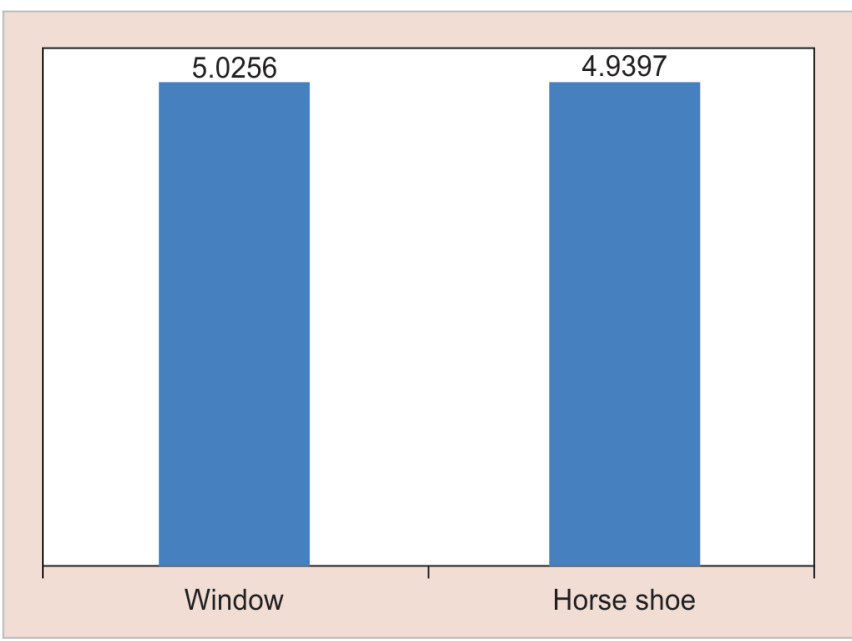

Fig. 2: Comparison of the mean denture retention at 3 months follow-up

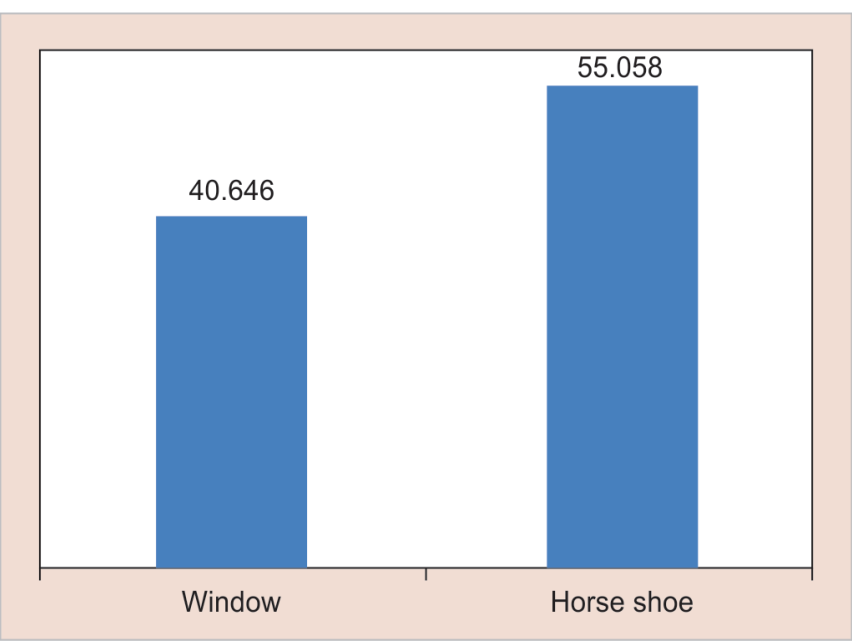

Fig. 3: Comparison of the mean bite force at 1 week

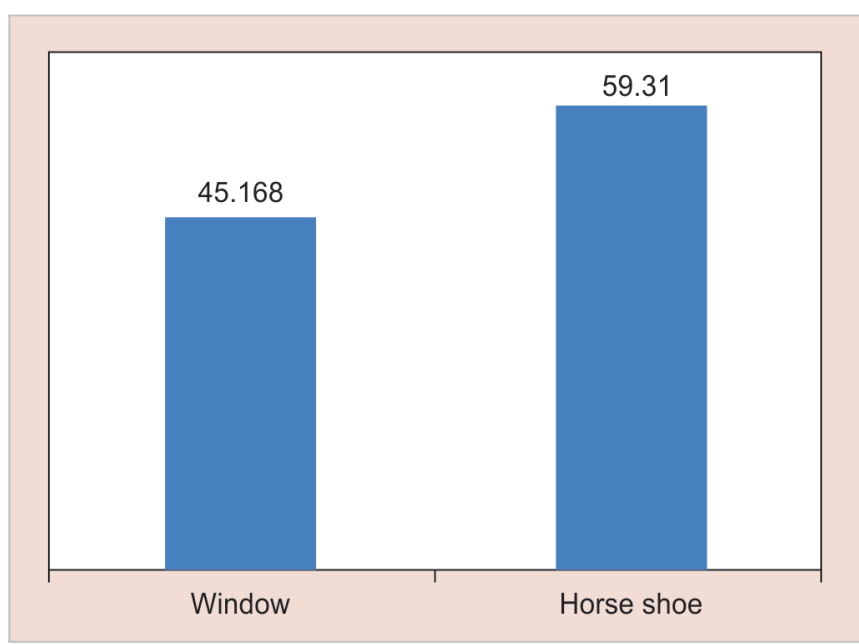

Fig. 4: Comparison of the mean bite force at 1 month

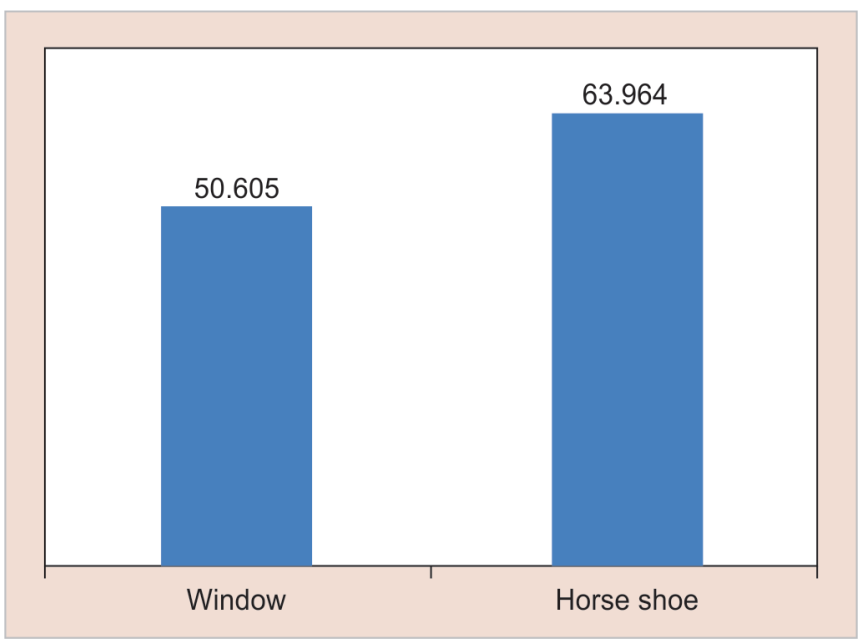

Fig. 5: Comparison of the mean bite force at 3 months

Table 2: Comparison of bite forces between the two dentures at different time intervals

\begin{tabular}{llllll}
\hline & Group & $N$ & Mean & Std. deviation & $P$ \\
\hline BF1 week & Window & 66 & 40.646 & 3.77210 & 2.83140 \\
BF1 month & Horse shoe & 66 & 55.058 & 3.65371 & $<0.001$ \\
& Window & 66 & 45.168 & 2.93769 & $<.001$ \\
BF3 months & Horse shoe & 66 & 59.310 & 2.78804 & $<0.001$ \\
& Window & 66 & 50.6050 & 3.24292 & \\
\hline
\end{tabular}

\section{Discussion}

The most common problem associated with torus palatinus is denture interference, leading to denture instability. ${ }^{15} \mathrm{~A}$ large torus palatinus with an undercut often complicates the placement of the tray when taking impressions or inserting the dentures, thereby reducing the retention and stability of acrylic dentures causing inflammation on the mucosa due to friction from the prosthesis. ${ }^{10}$

Due to complications such as nasal perforation, oroantral fistula formation, palatal tissue necrosis, and hematoma, ${ }^{16,17}$ associated with surgical removal, Valentine DC, suggested modifications in the design of a complete maxillary denture with a large midline window within a denture to accommodate the torus, as this would be a viable option for management of a small, midline torus. ${ }^{18}$

Abrams S suggested a Triple lamination technique, to help engage deep, soft-tissue undercuts in the anterior aspect of the maxilla. ${ }^{19}$ Using the triple lamination method, fabrication of an overdenture covering a torus palatinus, using a combination of denture base materials, was fabricated using the maxillary torus as a key element in anchoring the prosthesis, has also been reported. The thermoplastic flange provides a measure of flexibility, allowing the denture to seat over the torus. The resilient liner provides a cushion to diffuse the occlusal load, while the rigid acrylic base provides the support for the denture teeth, ${ }^{16}$ as reported by Abrams S, Hellen W. 
Rajeev V, Arunachalam R reported an innovative prosthodontic management for patients with torus by modifying the amount of tissue coverage with a denture with a window. ${ }^{13}$ Falatehan N, Anfelia reported that horseshoe-shaped dentures, ${ }^{14}$ as an option to relieve the tori from denture impingement. Eventually, the optimal retention and stability of the dentures can be maintained, oral health and quality of life can be improved, and the occurrence of TMD can be prevented. ${ }^{20}$

In the current study, there were $29(44 \%)$ male and $37(56 \%)$ female subjects, with maxillary tori. Among whom, we compared the denture with window and the horseshoe-shaped denture in terms of denture retention and Bite force.

Bite force is an indicator of the functional state of the masticatory system that results from the action of jaw elevator muscles modified by the craniomandibular biomechanics. ${ }^{21}$ Determination of individual bite force level has been widely used in dentistry, mainly to understand the mechanics of mastication for evaluation of the therapeutic effects of prosthetic devices and to provide reference values for studies on the biomechanics of prosthetic devices. 22

Bite force recorded in all three intervals of the study (1st week, 1st month and the 3rd month) was more in horseshoe group and it was statistically significant. This is in accordance with studies reported by Shala $\mathrm{K}$ et al, that bite force increases significantly with newly fit complete dentures, till it reaches the stationary state. However, the period towards reaching a stationary state varies greatly. ${ }^{23}$ Studies reported by Turker SB, suggest that increase in initial values of bite force results in better adaptation to dentures. Furthermore, duration of denture use was associated with higher satisfaction rates. ${ }^{24}$ However, one should consider other effective factors when comparing bite force measurement in research. ${ }^{25}$ The role of Prosthodontists is to have an understanding of the changes in the orofacial form, function and behavioral consequences and the possible social impact emerging from the complete loss of teeth. ${ }^{26}$

The retention measurements were performed three months post denture wear with the denture with the window and 3 months after modifying the denture to a horseshoe-shaped denture. However, the results of the experimental dislodgement tests were similar to previous studies by Fløystrandd F et al, which suggested that the ability to withstand tilting loads was insignificantly altered by reduction of the palatal coverage. ${ }^{27}$ There was not much significant difference between the two dentures in terms of their retentiveness as both showed approximately similar values.

The study participants adapted well to both the denture designs, in terms of palatal coverage. However, it is worth mentioning that, adaptation improved significantly with modification of the complete denture with window to the horseshoe-shaped complete denture.

The observation period of 3 months for each denture design served as a limitation of the study, in terms of bite force, as previous findings by Atkinson HF et al, state that this period is between 12 and 24 months. ${ }^{28}$ Further research to include chewing efficiency with both dentures designs is recommended.

\section{ConcLusion}

Complete dentures remain a viable and cost-effective treatment choice in the completely edentulous geriatric population. Some intraoral anatomical features can negatively affect certain patients and complicate prosthodontic intervention. In this study, the horseshoe-shaped complete denture proved to be an effective treatment option compared to the denture with the window. Futuristic methods need to be developed to restore and improve patient comfort, functional adaptation to dentures in the presence of unfavorable denture foundations.

\section{References}

1. The Glossary of Prosthodontic Terms. J Prosthet Dent 2005;94(1):10-92. DOI: 10.1016/j.prosdent.2016.12.001

2. Edwards LF, Boucher CO. Anatomy of the mouth in relation to complete denturesJ Am Dent Assoc 1942;29(3):331-345. DOI: 10.14219/jada.archive.1942.0019

3. HardyIR, Kapur KK. Posterior border seal-its rationaleand importance. J Prosthet Dent 1958;8(3):386-397. DOI: 10.1016/0022-3913 (58)90064-7

4. Jacobson TE, Krol AJ. A contemporary review of the factors involved in complete denture retention, stability, and support. Part I: retention. J Prosthet Dent 1983;49(1):5-15. DOI: 10.1016/0022-3913 (83) $90228-7$

5. Ali MSA, Al-Harbi FA. Posterior palatal seal area established in conventional and CAD/CAM fabricated complete denture techniques: clinical case study. J Dent Craniof Res 2016; 1;(1);3. DOI: 10.21767/2576-392X.100003

6. Bouquot JE. Common oral lesions found during a mass screening examination. J Am Dent Assoc 1986;112(1):50-57. DOI: 10.14219/jada. archive.1986.0007

7. Jainkittivong A, Apinhasmit W, Swasdison S. Prevalence and clinical characteristics of oral tori in 1,520 Chulalongkorn University Dental School patients. Surg Radiol Anat2007;29(2):125-131. DOI: 10.1007/s00276-007-0184-6

8. Hiremath V.K. Husein A. Mishra N. Prevalence of torus palatinus and torus mandibularis among Malay population. J Int Soc Prev Commun Dent 2011;1(2):60-64. DOI: 10.4103/2231-0762.97704

9. Preoteasa $\mathrm{E}$, Preoteasa $\mathrm{CT}$, losif $\mathrm{L}$, et al. Denture and overdenture complications. In: Emerg Trends Oral Health Sci Dent. London: InTech; 2015. 195. Available from: http://www.intechopen.com/books/ emerging-trends-in-oral-health-sciences-and-dentistry/dentureand-overdenture-complications. [Last accessed o 2021 Oct 1]

10. Al Quran FA, Al-Dwairi ZN. Torus palatinus and torus mandibularis in edentulous patients. J Contemp Dent Pract. 2006 May;7(2):112-119. PMID: 16685302

11. García-García AS, Martínez-González JM, Gómez-Font R, et al. Current status of the torus palatinus and torus mandibularis. Med Oral Patol Oral Cir Bucal 2010;15(2):e353-e360. DOI: 10.4317/ medoral.15.e353

12. Bhandari PP, Rathod P, Punga R, Torus mandibularis: excision and closure with cyanoacrylate tissue glue Int J Oral Care Res, 2016;4(2):134-138. DOI: 10.5005/jp-journals-10051-0029

13. Rajeev V, Arunachalam R. Innovative replication and recuperation of complex torus palatinus: a prosthodontic case report. World J Dent 2016;7(4):208-212. DOI: 10.5005/jp-journals-10015-1398

14. Falatehan N, Anfelia G. Nonsurgical approach for torus palatinus management in full denture rehabilitation. Sci Dent J 2020;4:124-128. DOI: 10.4103/SDJ.SDJ_21_20

15. Rezeki A, Koesmaningati $H$, Kusdhany LS. Reliability and validity of an Indonesian version of the patient's denture assessment (PDA): a self-assessment instrument for measuring patient satisfaction with complete dentures. J Int Dent Med Res 2017;10:449. Corpus ID: 121175187

16. Abrams S, Hellen W. Fabrication of an overdenture covering a torus palatinus using a combination of denture base materials: a case report. Dent Today 2006 Apr;25(4):74-77. PMID: 16646508.

17. Costello BJ, Betts NJ, Barber HD, et al. Preprosthetic surgery for the edentulous patients. Dent Clin North Am 1996 Jan;40(1):19-38. PMID: 8635621. 
18. Valentine DC. Conservative management of a pedunculated torus palatinus in an edentulous arch. Gen Dent 1983 May-Jun;31(3): 202-203. PMID: 6347804.

19. Abrams S. A technique for using maxillary anterior soft-tissue undercuts in denture placement: a case report. J Can Dent Assoc 2002 May;68(5):301-304. PMID: 12019041.

20. Limpuangthip N, Somkotra T, Arksornnukit M. Modified retention and stability criteria for complete denture wearers: a risk assessment tool for impaired masticatory ability and oral health-related quality of life. J Prosthet Dent 2018;120:43-49. DOI: 10.1016/j. prosdent.2017.09.010

21. Bakke M. Bite force and occlusion. Semin Orthod 2006;12:120-126. DOI: 10.1053/j.sodo.2006.01.005

22. Fernandes CP, Glantz PJ, Svensson SA, et al. A novel sensor for bite force determinations. Dent Mater 2003;19:118-126. DOI: 10.1016/ s0109-5641(02)00020-9

23. Shala K, Tmava-Dragusha A, Dula L, et al. Evaluation of Maximum Bite Force in Patients with Complete Dentures. Open Access Maced
J Med Sci 2018 Mar 13;6(3):559-563. DOI: 10.3889/oamjms.2018.141. PMID: 29610620; PMCID: PMC5874385.

24. Turker SB, Sener ID, Ozkan YK. Satisfaction of the complete denture wearers related to various factors. Arch Gerontol Geriatr 2009; 49(2):e126-e129. DOI: 10.1016/j.archger.2008.11.003

25. Koc $D$, Dogan $A$, Bek B. Bite force and influential factors on bite force measurements: a literature review. Eur J Dent 2010 Apr;4(2):223-232. PMID: 20396457; PMCID: PMC2853825.

26. Kumar L. Biomechanics and clinical implications of complete edentulous state. J Clin Gerontol Geriatr. 2014; 5:101-104. DOI: 10.1016/j.jcgg.2014.03.001

27. Fløystrand F, Karlsen K, Saxegaard E, et al. Effects on retention of reducing the palatal coverage of complete maxillary dentures. Acta Odontol Scand 1986 Apr;44(2):77-83. DOI: 10.3109/ 00016358609041311 . PMID: 3524095.

28. Atkinson HF, Ralph WJ. Tooth loss and biting force in man. J Dent Res 1973; 52:225-228. DOI: 10.1177/00220345730520020701 